Document downloaded from:

http://hdl.handle.net/10251/111630

This paper must be cited as:

Carrion, C.; Mulet Pons, A.; García Pérez, JV.; Carcel Carrión, JA. (2017). Ultrasonically assisted atmospheric freeze-drying of button mushroom. Drying kinetics and product quality. Drying Technology. 36(15):1814-1823. doi:10.1080/07373937.2017.1417870

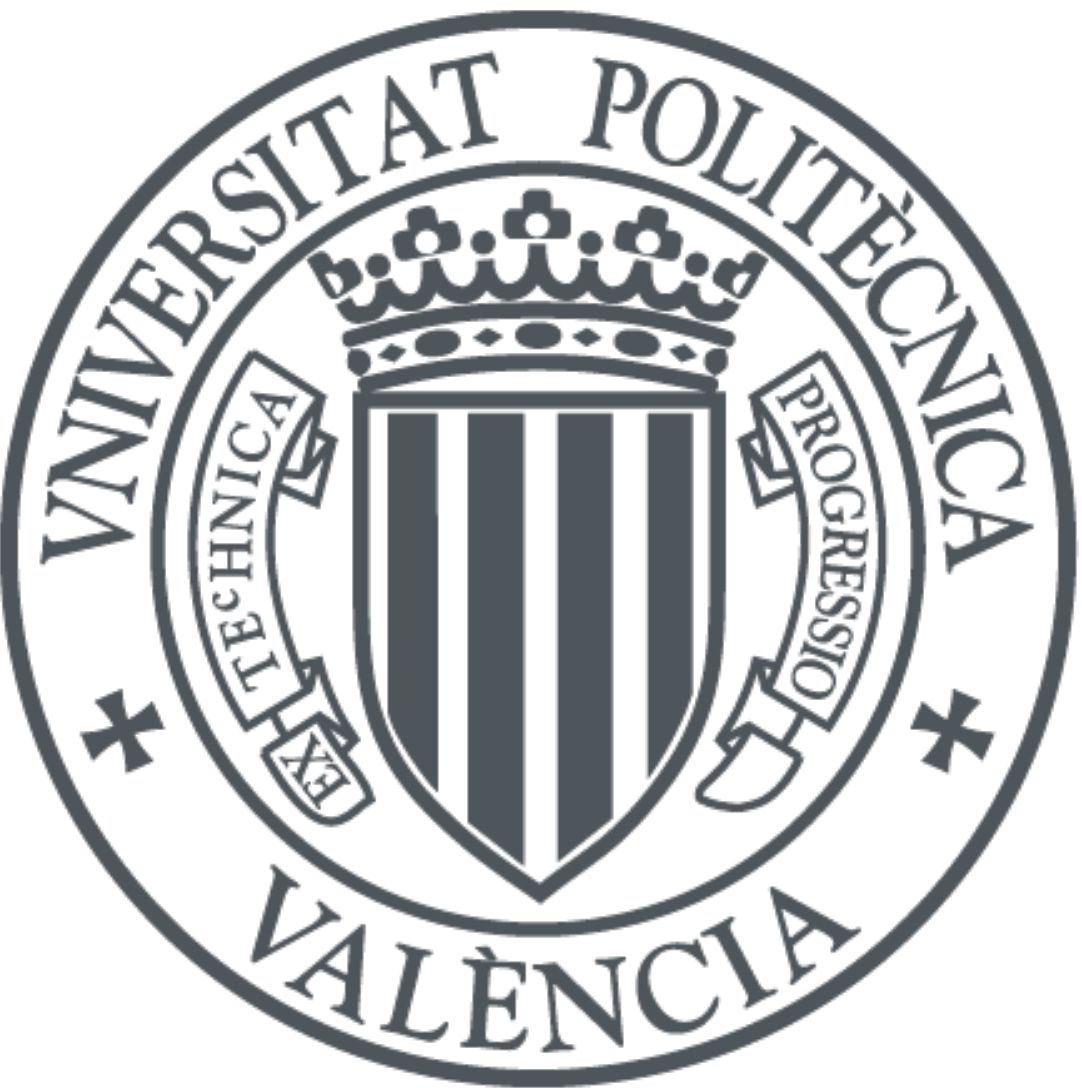

The final publication is available at

http://doi.org/10.1080/07373937.2017.1417870

Copyright Taylor \& Francis

Additional Information 

19

\title{
ULTRASONICALLY ASSISTED ATMOSPHERIC FREEZE-DRFYING OF BUTTON MUSHROMM. DRYING KINETICS AND PRODUCT QUALITY
}

\author{
Carrión, C., Mulet, A., García-Pérez, J. V., Cárcel, J. A.
}

ASPA group. Department of Food Technology. Universitat Politècnica de València.

Camino Vera s/n, 46022. Valencia. Spain

Tel.: +34 3879365 Email: jcarcel@tal.upv.es

*Corresponding author. Tel.: +34 96 3879376; Fax: +34 963879839

$17 \quad$ E-mail address: jcarcel@tal.upv.es

8 Postal address: Departamento de Tecnología de Alimentos. Universitat Politècnica de València. Camino de Vera s/n, 46022 Valencia (Spain). 
22 The aim of this work was to evaluate the feasibility of using power ultrasound to improve

23 the atmospheric freeze-drying of mushroom, as interesting alternative to vacuum freeze-

24 drying, considering not only kinetic effects but also the final quality. For that purpose,

25 mushroom slices (Agaricus bisporus) were dried $\left(-10^{\circ} \mathrm{C}\right.$ and $\left.2 \mathrm{~m} / \mathrm{s}\right)$ with $(24.6$ and 12.3

$26 \mathrm{~kW} / \mathrm{m}^{3} ; 21.9 \mathrm{kHz}$ ) and without ultrasound application. The application of ultrasound

27 significantly influenced the drying kinetics, increasing the effective diffusivity up to 280

$28 \%$ and shortening drying time up to $74 \%$. As for the quality parameters (color, texture,

29 rehydration and cell damage), no remarkable influence of the ultrasound application was

30 observed. Therefore, the application of power ultrasound during the atmospheric freeze-

31 drying of mushroom might be considered as an interesting technology providing that it

32 significantly increased the process kinetics without greatly affecting the quality of the final

33 product

34 Keywords: dehydration, moisture, effective diffusivity, drying time, quality. 


\section{INTRODUCTION}

Drying, one of the oldest food preservation techniques, makes it easier to handle food products and allows for a relatively low-cost storage [1]. One of the most widely used methods for drying vegetables and fruits is hot air convective drying [2]. However, the quality of the dehydrated products obtained is usually poor and it is characterized by a lower content of vitamins and other nutrients [3]. In addition, the high temperatures used induce structural changes [2]; these are more intense in high porosity products, such as the mushroom, whose porosity is between 25 and $50 \%$ according to Paudel et al. [4]. All these facts, coupled both with the fact that consumers are demanding greater product quality requirements and also the need to reduce the impact industry has on the environment, have led to more interest being shown in the development of alternative drying technologies [5].

As for the product quality, the vacuum freeze drying (VFD) process is probably the benchmark process because it preserves the nutritional characteristics of dried food products very well [6]. Nevertheless, the high processing cost, both from an energetic and economic point of view, and the difficulty of continuous operation constitute its main drawback. Atmospheric freeze drying (AFD) is an interesting alternative to reduce manufacturing costs, since it could combine the advantages of both vacuum freeze drying (high product quality) and convective drying (relative low process costs) [3]. However, it is a very slow process [7]. Therefore, the application of other technologies as additional sources of energy, such as ultrasound, could be interesting as a means of contributing to an intensification of the atmospheric freeze-drying process [2].

Unlike other non-conventional technologies, such as microwave, radio frequency or infrared radiation, ultrasound effects are not thermal but mainly mechanical. This avoids the risk of overheating the product with the consequent reduction in the final product quality [8]. Acoustic vibrations generate a succession of compressions and expansions 
of the material that produces a mechanical stress, similar to what happens to a sponge that is repeatedly squeezed and relaxed. Then, it is easier for the internal moisture to flow out to the surface of the sample [9]. As far as the ultrasound application during the AFD is concerned, several studies have shown a significant increase in the drying rate, reducing the processing time from 35 to $90 \%$ in products, such as apple [10], salted cod [11], eggplant [12] or carrot [13]. The magnitude of the ultrasound effects on convective drying can be influenced by process variables, such as drying temperature, air velocity, applied ultrasonic power and product structure [9]. Moreover, the viability of the ultrasound application should be evaluated by not only considering the kinetics of the process but also the quality of the dried product, since ultrasound is able to produce changes in the quality parameters, such as texture or color [11].

The button mushroom (Agaricus bisporus) is a widely cultivated and consumed fungus because of its nutritional characteristics and typical umami flavor. The cultivated mushroom is a highly perishable product with a short shelf life due to browning, opening umbrella and even decay. Therefore, a significant proportion of the production is usually dehydrated to expand the uses the mushroom can be put to [14]. In fact, the consumption of dehydrated mushrooms has increased in recent years, either as a dehydrated product itself or as an ingredient of numerous industrial products, such as creams or dehydrated soups. In this sense, physical properties of dried products, such as rehydration capacity or color, must also be taken into account. For these reasons, it is important to study the processes related to how this product is obtained.

The main aim of this work was to evaluate the feasibility of using power ultrasound to improve the AFD of mushroom, considering not only the kinetic effects but also its influence on some quality attributes. 


\section{Sample preparation}

88 The mushrooms (Agaricus bisporus) were purchased from a local market (Valencia, Spain). To ensure the homogeneity of raw material, the mushrooms chosen were collected and packed the day before processing. Mushroom slices ( $6 \mathrm{~mm}$ thick) were obtained using a household mandolin. Twelve samples were randomly placed in a custom sample holder which was wrapped in plastic film and place inside a freezer (Liebherr mod. SGN 3063) where were fast frozen at $-32^{\circ} \mathrm{C}$. After that samples were maintained at $-18 \pm 1^{\circ} \mathrm{C}$ until processing $(24 \mathrm{~h})$.

\section{Moisture content}

The moisture content was measured by placing ground samples in a vacuum oven at $70^{\circ} \mathrm{C}$ and $200 \mathrm{mmHg}$ until constant weight, following the AOAC standard method no. 934.06 [15]. The moisture measurements were taken in fresh, dried and rehydrated samples.

\section{Atmospheric freeze-drying experiments}

Atmospheric freeze-drying experiments were carried out in an ultrasound-assisted convective drier with air recirculation (Figure 1), previously described in the literature [8]. The equipment consists of a drying chamber excited by a piezoelectric transducer (21.9 $\mathrm{kHz}$ ) where the samples are placed. Air-velocity and temperature are controlled by means of PID control algorithms.

The drying experiments were carried out at a constant temperature of $-10^{\circ} \mathrm{C}$ and an air velocity of $2 \mathrm{~m} / \mathrm{s}$, without $\left(0 \mathrm{~kW} / \mathrm{m}^{3}, A F D-0\right)$ and with ultrasound application. When ultrasound was applied, two different power levels were tested: 12.3 and $24.6 \mathrm{~kW} / \mathrm{m}^{3}$ (AFD-12.3 and AFD-24.6, respectively). At least four replicates were performed for each 
110 drying condition tested. All of the experiments were considered to be finished when the

111 samples lost $85 \%$ of their initial weight. The drying kinetics was determined from the

112 initial moisture content of the mushroom slices and the sample weight measurements

113 during drying.

114 Vacuum freeze-drying experiments

115 Mushrooms samples were dried by vacuum freeze-drying (VFD) in a freeze drier (model

116 LYOQUEST-55; Azbil Telstar Technologies S.L.U., Terrassa, Spain). The freeze-drying

117 conditions were as follows: a condenser temperature of $-50 \pm 10^{\circ} \mathrm{C}$ and a pressure of 6

$118 \mathrm{~Pa}$. A total of 60 mushroom slices were dried and used for quality parameter

119 measurement as a quality reference.

120 Quality parameters

121 Color

122 The surface color of fresh, dried and rehydrated mushroom samples was determined by

123 measuring the CIELAB space color parameters $L^{*}$ (lightness/darkness), $a^{*}$

124 (redness/greenness) and $b^{*}$ (yellowness/blueness) with a CM-2500d colorimeter (Konica

125 Minolta, Japan). The readings were taken in triplicate at two different points on each

126 mushroom slice in fresh, dried (12 slices for each drying experiment) and rehydrated (5

127 slices per drying condition tested) samples. In the case of vacuum freeze drying

128 experiments, color measurements were carried out in 18 randomly selected samples.

129 The measurements were taken using a D65 illuminant reference system, at an

130 observation angle of $10^{\circ}$ and considering the excluded specular component (SCE).

131 Furthermore, the total color difference (Eq. 1), browning index (Eq. 2) and Chroma (Eq.

132 4) were calculated to describe the color change during processing. The total color

133 difference $\left(\Delta E^{\star}\right)$ denotes the color change in the reference material and is expressed as: 
Where subscript " $t$ " refers to the color of the treated sample values and "0" to the color of the fresh sample, used as the reference.

137 The Browning Index (BI) was calculated using Eq. 2 [16]:

$138 \quad \mathrm{BI}=100 \times \frac{X-0,31}{0,17}$

$140 \quad X=\frac{\left(a^{*}+1,75 \times L^{*}\right)}{\left(5,645 \times L^{*}+a^{*}-3,012 \times b^{*}\right)}$

141 Chroma $\left(C^{*}\right)$ is a measurement of the color saturation; thus, high values indicate highly saturated colors. The $C^{*}$ value was calculated as follows [17]:

The texture of the fresh and rehydrated samples was determined by performing a texture profile analysis (TPA) using a texture analyzer (TA-XT2, SMS, United Kingdom). Double compression tests were performed up to $50 \%$ deformation of the original sample height, using a test-speed of $2 \mathrm{~mm} / \mathrm{s}$. An aluminum cylindrical probe of $50 \mathrm{~mm}$ diameter was used and at least 5 replicates were performed for each drying experiment. The test was carried out at room temperature.

151 From the resulting force-time curve, four parameters were obtained. Hardness $(N)$ is the force necessary to attain a given deformation and is calculated as the peak force during the first compression cycle. Cohesiveness is the strength of the internal bonds and is calculated as the ratio $\left(A_{2} / A_{1}\right)$ of positive force area obtained during the second 
compression $\left(A_{2}\right)$ and the obtained during the first compression $\left(A_{1}\right)$. Elasticity is the rate at which a deformed material goes back to its previous condition after deforming force is removed and is calculated as the distance of the detected height during the second compression divided by the original compression distance. Finally, chewiness is the energy required to masticate a solid food product to state ready for swallowing and is calculated as the product of hardness, cohesiveness and elasticity [18].

\section{Rehydration}

Rehydration experiments were carried out for each drying condition tested by immersing five dried mushroom slices into distilled water at $25 \pm 1^{\circ} \mathrm{C}$ under constant agitation. Every 10 seconds, the samples were removed from the water, superficially blotted with tissue paper to remove the surface water and weighed. Rehydration was extended until a constant value was reached ( 3 consecutive measurements with a weight variation of under $0.05 \mathrm{~g}$ ). Four replicates were performed for each atmospheric freeze-drying condition tested and six for vacuum freeze-drying experiments. The rehydration time, final moisture content and rehydration kinetics were obtained for each kind of sample.

\section{Cell damage}

The cell damage caused by the drying treatment was determined by electrolyte leakage measurement, which is based on the principle that damage to the cell membranes causes a leak of solutes into the apoplastic water [19]. For this purpose, two mushroom slices from each drying experiment carried out, fresh or dried, were incubated at $25 \pm 1$ ${ }^{\circ} \mathrm{C}$ in $25 \mathrm{~mL}$ deionized distilled water in a $250 \mathrm{~mL}$ beaker for $24 \mathrm{~h}$. After that, the liquid conductance was measured using a conductivity meter (COND 7, LabProcess, Spain). The procedure used was modified from the used by Gómez-Galindo et al. [20]. In the present study, the relative parameter that permit the comparison between treatments is 
obtained by dividing the conductivity measured in the liquid over the dry matter of the samples used for each test.

\section{Water activity}

The water activity of the dried mushroom slices was measured using an AW SPRINT TH500 equipment (Novasina, Switzerland) at a temperature of $25 \pm 1^{\circ} \mathrm{C}$.

\section{Drying and rehydration modelling}

A diffusion model was used to mathematically quantify the drying and rehydration kinetics (Eq. 5). This model considers the internal transport of moisture by diffusion as the only mechanism that describes drying or rehydration kinetics and has been widely used to mathematically describe both kind of processes $[21,22]$. The influence of external resistance to transport was neglected, assuming that the moisture content of the surface reached equilibrium at the beginning of the operation. It was also assumed that the samples exhibited infinite slab behavior and, therefore, the flux of moisture during the process occurred in a single direction. It was considered that the effective moisture diffusivity was constant throughout the operation [23] and that the sample was isotropic and homogeneous. However, this latter condition, considered mainly in hot air-drying processes, is not accomplished under atmospheric freeze-drying conditions. In this case, the solid is composed of two main layers: a dried outer layer that expands during drying and a frozen inner core that shrinks. Therefore, the solid is neither homogeneous nor isotropic and then, under atmospheric freeze-drying conditions, the theoretical diffusional model becomes an empirical one. Even so, this model has been previously used under these conditions with acceptable fitting results [24] and permits the comparison of different treatment kinetics.

$\frac{\partial W(x, t)}{\partial t}=D_{e} \frac{\partial^{2} W(x, t)}{\partial x^{2}}$ 
203 Where $W$ is the local moisture content (kg water $/ \mathrm{kg}$ dry matter, d.m.); $D_{e}$ is the effective 204 moisture diffusivity $\left(\mathrm{m}^{2} / \mathrm{s}\right)$; $t$ is the time (s); and $x$ is the direction of the water transport 205 (m). Eq. 5 was solved by considering that the initial sample moisture was uniform at the 206 beginning of the process and the moisture transport was symmetrical on both sides of 207 the symmetry plane of the mushroom slices (Eq. 6):

$208 \quad \frac{\partial W(0, t)}{\partial x}=0$ Eq. 6

209

210

211

212

213

214

215

217

218

219

220
Eq. 7

As the external resistance to moisture transport was neglected, the drying and rehydration kinetics were controlled solely by the diffusion transport of internal moisture (Eq. 7).

$W(L, t)=W_{e q}$

Where $L$ is the thickness of the sample and $W_{e q}$ is the equilibrium moisture content $(\mathrm{kg}$ water/kg d.m.). When modelling the drying process, this equilibrium moisture content was calculated from the desorption isotherm for mushroom, reported by Guizani et al. [25]. In the case of rehydration, the equilibrium moisture was experimentally measured.

The analytical solution of the model was integrated for the sample volume (Eq. 8). The resulting model was used to predict the evolution of the moisture sample content during the operation.

$W=W_{e q}+\left(W_{0}-W_{e q}\right)\left[2 \sum_{\mathrm{n}=0}^{\infty} \frac{1}{\lambda_{\mathrm{n}}^{2} L^{2}} \mathrm{e}^{-D_{e} \lambda_{n}^{2} t}\right]$

Eq. 8

221 Where $W_{0}$ is the initial moisture content of the samples and $\lambda_{n}$ the eigenvalues that fulfill

222 the condition $\lambda_{n} L=(2 n+1) \cdot \pi / 2$. 
223 The model was fitted to the experimental data by identifying the effective diffusivity $\left(D_{e}\right)$

224 that minimizes the sum of the squared differences between the experimental and 225 calculated moisture content. For that purpose, the Generalized Reduced Gradient 226 optimization available in the Solver tool of Microsoft Excel TM (Microsoft Corporation, 227 Seattle, USA) was used.

228 The percentage of explained variance (Eq. 9) was used to quantify the goodness of the 229 model fitting.

$230 \operatorname{VAR}(\%)=\left[1-\frac{S_{x y}^{2}}{S_{y}^{2}}\right] \cdot 100$ Eq. 9

231 Where $S^{2}{ }_{x y}$ is the standard deviation of the estimation and $S^{2}{ }_{y}$ is the standard deviation 232 of the sample.

\section{Statistical analysis}

234 An analysis of variance (ANOVA) was carried out and the Least Significant Difference 235 (LSD) intervals were determined using the Statgraphics Plus 5.1 software (Statistical 236 Graphics Corporation, Warrenton, USA) to establish whether the different ultrasonic power levels applied significantly $(p<0.05)$ influenced both the kinetics and the quality parameters of the dried mushroom.

\section{RESULTS}

\section{Experimental drying}

241 The average initial moisture content of the mushrooms used in this work was $10.48 \pm$ $2420.90 \mathrm{~kg}$ water $/ \mathrm{kg}$ dry matter (d.m.). After the different AFD experiments, the average final moisture content of the dried samples reached $0.12 \pm 0.05 \mathrm{~kg}$ water $/ \mathrm{kg} \mathrm{d.m.,} \mathrm{while} \mathrm{for}$ vacuum freeze-dried samples it was $0.07 \pm 0.01 \mathrm{~kg}$ water $/ \mathrm{kg}$ d.m. Every dehydrated sample exhibited water activity values of under 0.6 to ensure their stability. 
246 Ultrasound application significantly increased $(p<0.05)$ the drying rate and reduced the 247 drying time. This reduction was dependent on the ultrasonic power applied (Figure 2). 248 Thus, the time required to obtain a moisture content of $0.75 \mathrm{~kg}$ water $/ \mathrm{kg} \mathrm{d.m}$. was reduced by $58.5 \%$ when $12.3 \mathrm{~kW} / \mathrm{m}^{3}$ was applied if compared to experiments without ultrasound application: from $84 \pm 10$ to $35 \pm 10$ hours. When the highest ultrasound power tested was applied $\left(24.6 \mathrm{~kW} / \mathrm{m}^{3}\right)$, the reduction was $74.2 \%$, requiring a drying time of only $22 \pm 4$ hours. The figures of standard deviation of drying time show the variability of the experimental results that can mainly be attributed to the raw matter.

\section{Modeling the drying process}

255

The mathematical modeling made it possible to quantify the influence of ultrasound application on the mass transfer. The proposed model exhibited an adequate fit to the experimental data, since the values of the percentage of explained variance obtained were above $98 \%$ in every case. Moreover, the trend of the experimental and calculated data was very similar (Figure 2). Thus, the hypothesis of neglecting the external mass transfer resistance was adequate in the drying conditions tested.

The results of the modeling showed that the values of the effective diffusivity $\left(D_{e}\right)$ identified by the model increased significantly $(p<0.01)$ as the applied ultrasound power increased. Thus, when $12.3 \mathrm{~kW} / \mathrm{m}^{3}$ ultrasound power was applied, $D_{e}$ was $159.2 \%$ higher than the value obtained in the experiments without ultrasound application: from $2.7 \pm 0.5$ to $7 \pm 2 \cdot 10^{-11} \mathrm{~m}^{2} / \mathrm{s}$. On the other hand, when the highest ultrasound power tested $(24.6$ $\mathrm{kW} / \mathrm{m}^{3}$ ) was applied, the increase was more significant $(280.6 \%)$, reaching an average value of $10.3 \pm 0.4 \cdot 10^{-11} \mathrm{~m}^{2} / \mathrm{s}$.

Previous studies indicate that the influence of ultrasound on the identified effective diffusivity is related to the mechanical effects. Thus, the repeated compression and expansion in both the air-solid interface and in the structure of the product produced by 
271 ultrasound generates the process known as the "sponge effect" [26, 8] At microscopic

272 level, the product could be likened to a sponge that is being tightened and relaxed

273 repeatedly. The stress generated facilitates the exit of liquid and vapor from the inner

274 parts of the sample to its surface during the compression phase. The forces involved in

275 this process may be higher than the surface tension that holds the water molecules inside

276 the capillaries of the sample and mechanical stress can create microchannels that make

277 mass exchange with the outside even easier [27].

278 Influence of ultrasound application on the dried mushroom quality

279 Color

280 The results showed that in general, it can be stated that drying produced some effects

281 on the color of mushrooms (Table 1). Thus, drying decreased $(p<0.05)$ the luminosity of 282 the dried samples $\left(L^{*}\right)$ and increased their yellowness $\left(b^{*}\right)$. On the contrary, the 283 parameter $a^{*}$ was not significantly $(p<0.05)$ affected by the drying. The application of ultrasound during AFD produced a greater decrease in parameter $L^{*}(p<0.05)$ and an increase in the figure of $a^{*}$, which leads to an appearance of red tones. As regards parameter $b^{*}$, the ultrasound application did not generate significant changes in this color variable. The ultrasound power lever used did not significantly influence the increase in these three parameters.

The total color difference between dried and fresh samples (Table 1) showed that the AFD generated a slight color change, similar to that produced by VFD. The ultrasound application during AFD significantly increased the total color difference $(p<0.05)$.

As concerns the Browning Index, the atmospheric freeze-dried samples with ultrasound application exhibited significantly higher values compared to those dried without ultrasound assistance (Table 1). The ultrasound power level used did not affect the Browning Index results. Similar results were obtained by Santacatalina et al. [28] in the 
case of the ultrasonically assisted atmospheric freeze drying $\left(-10^{\circ} \mathrm{C}\right)$ of apple. These authors attributed the darkening of the dried samples to a possible thermal effect generated by ultrasound on the surface of the sample. On the other hand, the Chroma results showed no significant differences between the samples dried using the different drying methods tested (Table 1).

As to the influence of rehydration on the sample color, while dried mushroom slices maintained a relatively similar color to that of the fresh mushrooms, the rehydrated samples exhibited a significant darkening, as can be observed in Figure 3. Thus, the Browning Index measured in the rehydrated samples was much higher $(346 \pm 184)$ than the value of the dried mushroom slices $(28.01 \pm 8$ for AFD-0). This darkening took place regardless of the drying method used. The phenomenon could be related to enzymatic reactions, specifically to the activation of the enzyme polyphenoloxidase. The enzyme is kept latent in the dried slices and activated during product rehydration [29]. AhmadQasem et al. [30] obtained a similar effect on freeze dried apple. These authors pointed out that the freeze drying does not inactivate these compounds that act against elements prone to be oxidized at the moment in which the water content is recovered. Therefore, it would be desirable to carry out pre-treatments, such as blanching for the purposes of inactivating the enzymes.

In any case, Chroma showed that the vacuum freeze-dried and subsequently rehydrated slices had a significantly $(p<0.05)$ more saturated color $(43 \pm 5)$ than those that had been atmospheric freeze-dried $(23 \pm 4)$. This could be explained by the vacuum conditions of the process, which could contribute to an effect on the microstructure of the mushroom that would help to release more oxidative compounds. 
322 The influence of the drying conditions applied in the instrumentally determined textural 323 parameters of the rehydrated mushroom samples was also addressed. The results showed that the hardness value of the rehydrated samples was much lower than that of the fresh samples, regardless of the drying method used (Table 2). This may probably be due to the degradation of the structure generated by both the previous freezing of the samples and the drying operation, which prevents the initial structural condition from being reached after the rehydration. The differences found between the samples dried using the different drying methods tested, although significant $(p<0.05)$, were small compared to the large changes observed with respect to the initial texture of the fresh mushroom. In any case, the AFD-24.6 samples presented lower hardness values than the AFD-12.3 and AFD-0 ones. Ozuna et al. [11] obtained similar results in the lowtemperature drying of salted cod. These authors attributed this fact to the mechanical effects caused by the application of ultrasound that affect the internal structure, softening the product. Then, the higher the power applied the greater the ultrasonic effects. In contrast, the VFD samples showed the highest hardness value, which could be attributed to the better maintenance of a rigid structure during drying.

The chewiness of the rehydrated mushroom slices behaved similarly to the hardness (Table 2). On the contrary, the cohesiveness and the elasticity significantly $(p<0.05)$ increased in line with the amount of ultrasonic power applied (Table 2). For both parameters, the values obtained in the case of vacuum freeze-dried samples were lower, the difference being significant $(p<0.05)$. This may be attributed to a rupture of the rehydrated sample during the first compression of the test so that the sample did not recover its initial height. 
347 The rehydration operation cannot be considered as simply the opposite of the drying 348 process. Irreversible structural changes are generated during food drying and this may affect the rehydration capacity of the samples, preventing the dried product from recovering all the moisture content it possessed when fresh. Thus, the rehydration capacity is dependent on the degree of cellular and structural alteration [31]. In this sense, the time needed for the dried samples to reach a moisture content of $2.5 \mathrm{~kg}$ water / kg d.m. differed significantly depending on the drying conditions considered (Table 3). Thus, the rehydration of the vacuum freeze-dried samples was faster than that of the AFD-0 samples. On the other hand, ultrasound application during AFD lengthened the rehydration time; the higher the ultrasonic power tested, the longer the time. This could be explained by some effects that ultrasonic waves exerted on the structure of the mushroom slices, making rehydration difficult. Even so, it must be highlighted that, as a general rule, rehydration was a rapid process that took less than 220 seconds in every case studied.

After rehydration, the final moisture content achieved by the AFD samples was not significantly different $(p<0.05)$, regardless of the application of ultrasound or the acoustic power applied (Table 3). However, this value was significantly higher $(p<0.05)$ in the case of the VFD samples. This could be attributed to both the lower drying temperature and the vacuum action that could limit the collapse of the structure and then facilitate the subsequent rehydration.

The rehydration of plant tissues is made up of three simultaneous phenomena: water absorption, swelling and solute leaching [31]. Therefore, during rehydration there is not only a positive flow of water into the sample, but also a less important flow of soluble solids from the material to the soaking water. This latter flow was not considered in the modelling and it was assumed that the increase in the weight of the samples during 
rehydration was only due to the increase in their water content. Therefore, in this case, the rehydration kinetics was determined from the moisture content of the samples at the beginning of the rehydration and the variation of the weight of the samples during the process. The rehydration kinetics was modeled using the same model that was used to model the drying experiments and the effective diffusivity of rehydration $\left(D_{\text {er }}\right)$ was identified.

The fitting of the model to the rehydration experimental data of AFD samples was satisfactory since the percentage of explained variance was above $98 \%$. Moreover, as can be observed in Figure 4, the calculated data followed a similar trend to the experimental. On the contrary, the percentage of explained variance obtained for VFD samples was relatively low. In this case, the rehydration occurred in $10 \pm 1$ seconds and it is likely that different transport mechanisms other than diffusion were also significant.

As regards the effective rehydration diffusivity values identified for AFD samples, no significant differences $(p<0.05)$ were found between treatments. Therefore, the application of ultrasound during AFD was found to have no influence on the rehydration kinetics (Table 3).

\section{Cell damage}

The cell damage induced by processing was estimated from the measurement of the conductivity of a solution in contact with different dried samples for $24 \mathrm{~h}$, as explained in the materials and methods section. As can be observed in Figure 5, the treatment significantly increased the measured conductivity compared to the fresh samples. This means a great impact on cell damage. However, an important part of the generated cell damage can be attributed to the fact that the sample freezes prior to drying. This can be observed in the conductivity value obtained for samples that were only frozen and thawed (Figure 5, THAWED bar). This value represents $82 \%$ of the total cell damage 
generated by the atmospheric freeze-drying without ultrasound application (AFD-0) and $60 \%$ in the case of the vacuum freeze drying (VFD) (Figure 5). This cell damage could be explained by the growth of ice crystals during freezing that break, push or compress the cells [32].

The influence of ultrasound application during AFD on cell damage depended of ultrasonic power considered. Thus, while the differences between AFD-0 and AFD-12.3 samples were not significant $(p<0.05)$, AFD-24.6 samples showed a significantly $(p<0.05)$ higher figure of conductivity (Figure 5$)$. The mechanical stress produced by ultrasound can affect the cell structure and the higher the ultrasonic power applied the greater the effect.

The cell damage of VFD samples was similar to those found for AFD-24.6. This fact can be related with the shrinkage of samples during drying. Thus, while it was observed a slight shrinkage of AFD samples, VFD ones preserve the initial volume of fresh samples. In this case, the vacuum applied during drying can prevent the shrinkage and this effect can induce the some cracks in the AFD sample structure due to its difficulty adapting to the loss of water. This idea agree with the fact VFD develop a structure more rigid and porous than AFD that allow a faster rehydration process, and provide samples with lower elasticity and cohesiveness how it is showed by the obtained rehydration and texture data.

\section{CONCLUSIONS}

The application of power ultrasound during the atmospheric freeze drying of mushrooms significantly shortened the process; the more ultrasonic power applied, the shorter the drying time. As regards the influence on quality parameters, ultrasonically assisted atmospheric freeze-drying produced dried samples with a lower degree of luminosity, higher red tones and a similar rehydration rate. The rehydrated samples presented lower values of hardness and chewiness but greater cohesiveness and elasticity. The degree 
423 of cellular damage was similar to that in the vacuum freeze-dried samples. All these 424 differences became greater as the amount of ultrasonic power applied increased but, 425 even though they were significant, they were not important in absolute values. Therefore, 426 ultrasound represents an interesting means of significantly increasing the drying rate 427 without producing important effects on the final quality of mushrooms.

\section{ACKNOWLEDGEMENTS}

429 The authors acknowledge the financial support of the Generalitat Valenciana 430 (PROMETEOII/2014/005) and INIA-ERDF (RTA2015-00060-C04-02). 


\section{REFERENCES}

434 1. Alves-Filho, O.; Eikevik, T.; Mulet, A.; Garau, C.; Rossello, C. Kinetics and 435 mass transfer during atmospheric freeze drying of red pepper. Drying $436 \quad$ Technology $2007,25,1155-1161$.

2. Puig, A.; Pérez-Munuera, I.; Cárcel, J.A.; Hernando, I.; García-Pérez, J.V. Moisture loss kinetics and microstructural changes in eggplant (Solanum melongena L.) during conventional and ultrasonically assisted convective drying. Food and Bioproducts Processing 2012, 90, 624-632.

3. Li, S.; Stawczyk, J.; Zbicinski, I. CFD model of apple atmospheric freeze drying at low temperature. Drying Technology 2007, 25, 1331-1339.

4. Paudel, E.; Boom, R.M.; Van Der Sman, R.G.M. Effects of porosity and thermal treatment on hydration of mushrooms. Food Bioprocess Technology 2016, 9, 511-519.

5. Musielak, G.; Mierzwa, D.; Kroehnke, J. Food drying enhancement by ultrasound - A review. Trends in Food Science \& Technology 2016, 56, $126-$ 141.

6. Claussen, I.C.; Ustad, T.S.; Strommen, I.; Walde, P.M. Atmospheric freezedrying - A review. Drying Technology 2007, 25, 957-967.

7. Bantle, M.; Eikevik, T.M. Parametric study of high-intensity ultrasound in the atmospheric freeze drying of peas. Drying Technology 2011, 29, 1230-1239.

8. García-Pérez, J.V.; Cárcel, J.A.; Riera, E.; Rosselló, C.; Mulet, A. Intensification of low-temperature drying by using ultrasound. Drying Technology 2012, 30, 1199-1208. 
9. Cárcel, J.A.; García-Pérez, J.V.; Riera, E.; Rosselló, C.; Mulet, A.; Ultrasonically assisted drying. In Ultrasound in Food Processing; Villamiel, M., García-Pérez, J.V., Montilla, A., Cárcel, J.A., Benedito, J., Eds.; John Wiley \& Sons Ltd.: United Kingdom, 2017; 371-391.

10. Brines, C.; Mulet, A.; García-Pérez, J.V.; Riera, E.; Cárcel, J.A. Influence of the ultrasonic power applied on freeze drying kinetics. Physics Procedia $2015,70,850-853$.

11. Ozuna, C.; Cárcel, J.A.; Walde, P.M.; García-Pérez, J.V. Low temperature drying of salted cod (Gadus morhua) assisted by high power ultrasound: kinetics and physical properties. Innovative Food Science and Emerging Technologies 2014, 23, 146-155.

12. Santacatalina, J.V.; Soriano, J.R.; Cárcel, J.A.; García-Pérez, J.V. Influence of air velocity and temperature on ultrasonically assisted low temperature drying of eggplant. Food and Bioproducts Processing 2016, 100, 282-291.

13. Cárcel, J.A.; García-Pérez, J.V.; Riera, E.; Rosselló, C.; Mulet, A.; Drying assisted by power ultrasound. In Modern Drying Technology Volume 5: Process intensification; Tsotsas, E., Mujumdar, A.S., Eds.; Wiley-VCH.: Germany, 2014; 237-273.

14. Pei, F.; Yang, W.; Shi, Y.; Sun, Y.; Mariga, A.M.; Zhao, L.; Fang, Y.; Ma, N.; An, X.; Hu, Q. Comparison of freeze drying with three different combinations of drying methods and their influence on colour, texture, microstructure and nutrient retention of button mushroom (Agaricus bisporus) slices. Food Bioprocess Technology 2014, 7, 702-710.

15. AOAC, Association of Official Analytical Chemist. Official methods of analysis; Arlington: EEUU, 1997. 
16. Mohapatra, D.; Bira, Z.M.; Kerry, J.P.; Frías, J.M.; Rodrigues, F.A. Postharvest hardness and color evolution of white button mushrooms (Agaricus bisporus). Journal of Food Science 2010, 75, 146-152.

17. Argyropoulos, D.; Khan, M.T.; Muller, J. Effect of air temperature and pretreatment on color changes and texture of dried Boletus edulis mushroom. Drying Technology 2011, 29, 1890-1900.

18. Szczesniak, A.S. Classification of textural characteristics. Journal of Food Science 1963, 28, 385-389.

19. Lindén, L.; Palonen, P.; Lindén, M. Relating freeze-induced electrolyte leakage measurements to lethal temperature in red raspberry. Journal of the American Society for Horticultural Science 2000, 125, 429-435.

20. Gómez-Galindo, F.; Toledo, R.T.; Sjöholm, I. Tissue damage in heated carrot slices. Comparing mild hot water blanching and infrared heating. Journal of Food Engineering 2005, 67, 381-385.

21. Garau, M.C.; Simal, S.; Femenia, A.; Rossello, C. Drying of orange skin: drying kinetics modelling and functional properties. Journal of Food Engineering 2006, 75, 288-295.

22. Garcıa-Pascual, P.; Sanjuán, N.; Melis, R.; Mulet, A. Morchella esculenta (morel) rehydration process modelling. Journal of Food Engineering 2006, 72, 346-353.

23. Do Nascimento, E.M.G.C; Mulet, A.; Ramírez-Ascherí, J.L.; Piler De Carvalho, C.W.; Cárcel, J.A. Effects of high-intensity ultrasound on drying kinetics and antioxidant properties of passion fruit peel. Journal of Food Engineering 2016, 170, 108-118. 
24. Moreno, C.; Brines, C.; Mulet, A.; Rosselló, C.; Cárcel, J.A. Antioxidant potential of atmospheric freeze-dried apples as affected by ultrasound application and sample surface. Drying Technology 2017, 35, 957-968.

25. Guizani, N.; Rahman, M.S.; Klibi, M.; Al-Rawahi, A.; Bornaz, S. Thermal characteristics of Agaricus bisporus mushroom: freezing point, glass transition and maximal-freeze-concentration condition. International Food Research Journal 2013, 20, 1945-1952.

26. Gallego-Juárez, J. A.; Rodríguez-Corral, G.; Gálvez-Moraleda, J. C.; Yang, T.S. A new high-intensity ultrasonic technology for food dehydration. Drying Technology 1999, 17, 597-608.

27. Cárcel, J.A.; García-Pérez, J.V.; Benedito, J.; Mulet, A. Food process innovation through new technologies: Use of ultrasound. Journal of Food Engineering 2012, 110, 200-207.

28. Santacatalina, J.V.; Guerrero, M.E.; García-Pérez, J.V.; Mulet, A.; Cárcel, J.A. Ultrasonically assisted low-temperature drying of desalted codfish. LWTFood Science and Technology 2016, 65, 444-450.

29. Fang, T.T.; Footrakul, P.; Luh, B.S. Effects of blanching, chemical treatments and freezing methods on quality of freeze-dried mushrooms. Journal of Food Science 1971, 36, 1044-1048.

30. Ahmad-Qasem, M.H.; Santacatalina, J.V.; Barrajón-Catalán, E.; Micol, V.; Cárcel, J.A.; García-Pérez, J.V. Influence of drying on the retention of olive leaf polyphenols infused into dried apple. Food Bioprocess Technology 2015, 8, 120-133.

31. Krokida, M.K.; Marinos-Kouris, D. Rehydration kinetics of dehydrated products. Journal of Food Engineering 2003, 57, 1-7. 
32. Voda, A.; Homan, N.; Witek, M.; Duijster, A.; Van Dalen, G.; Van Der Sman, R.; Nijsse, J.; Van Vliet, L.; Van As, H.; Van Duynhoven, J. The impact of freeze-drying on microstructure and rehydration properties of carrot. Food Research International 2012, 49, 687-693. 


\section{FIGURE CAPTIONS}

Figure 1. Ultrasonically assisted atmospheric freeze drier. A. Fan; B. Temperature sensor, Pt-100; C. Temperature and relative humidity sensor; D. Anemometer; E. Ultrasonic transducer; F. Vibrating drying chamber; G. Sample holder; H. Retreating pipe; I. Vertical displacement mechanism; J. Weighting module; K. Heat exchanger; L. Electric resistance; M. Desiccant material trays; N. Computer, O. Amplifier; P. Resonance dynamic control.

Figure 2. Experimental and model calculated drying kinetics $\left(-10^{\circ} \mathrm{C}\right.$ and $\left.2 \mathrm{~m} / \mathrm{s}\right)$ of mushroom slices, atmospheric freeze-dried without (AFD-0) and with ultrasound application $(21.9 \mathrm{kHz})$ at different power levels (AFD-12.3 and AFD-24.6 at 12.3 and $24.6 \mathrm{~kW} / \mathrm{m}^{3}$ respectively).

Figure 3. Fresh mushroom slices, dried by atmospheric freeze-drying without (AFD-0) and with ultrasound application, at 12.3 (AFD-12.3) and $24.6 \mathrm{~kW} / \mathrm{m}^{3}$ (AFD24.6), and dried by vacuum freeze-drying (VDF).

Figure 4. Experimental and model calculated rehydration kinetics of mushroom slices dried by atmospheric freeze-drying without (AFD-0) and with ultrasound application (AFD-12.3 and AFD-24.6; 12.3 and $24.6 \mathrm{~kW} / \mathrm{m}^{3}$ respectively)) and by vacuum freeze drying (VFD).

Figure 5. Influence of the treatment on the conductivity of a solution in contact with samples for $24 \mathrm{~h}$ as a measurement of cell damage. Average values and LSD intervals for fresh, thawed, atmospheric freeze-dried without (AFD-0) and with (AFD-12.3 and AFD-24.6) ultrasound application and vacuum freeze-dried mushroom slices (VFD). 
560 Table 1. CIELAB space color parameters $L^{*}, a^{*}$ and $b^{*}$ of the fresh (F), atmospheric

561

562

563

564

565

566

567

568

569

570

571

572

573

574

575

576

577

578

579 freeze-dried without (AFD-0) and with (AFD-12.3 and AFD-24.6) ultrasound application (12.3 and $24.6 \mathrm{~kW} / \mathrm{m}^{3}$ respectively) and vacuum freeze-dried mushroom slices (VFD). Total color difference $\left(\Delta E^{*}\right)$ from fresh values, browning index $(\mathrm{BI})$ and Chroma $\left(C^{*}\right)$. Mean values and standard deviation. Equal letters in the same raw indicate homogeneous groups obtained from LSD intervals $(p<0.05)$.

Table 2. Textural parameters of fresh samples (FRESH), rehydrated after atmospheric freeze-drying without (AFD-0) and with (AFD-12.3 and AFD-24.6) ultrasound application (12.3 and $24.6 \mathrm{~kW} / \mathrm{m}^{3}$ respectively) and by vacuum freeze-drying (VFD). Mean values and standard deviation. Equal letters in the same column indicate homogeneous groups obtained from LSD intervals $(p<0.05)$.

Table 3. Rehydration time $(t)$, final moisture content achieved $\left(x_{w f}\right)$ and rehydration identified effective diffusivity $\left(D_{e r}\right)$ of atmospheric freeze-dried mushroom slices without (AFD-0) and with (AFD-12.3 and AFD-24.6) ultrasound application (12.3 and $24.6 \mathrm{~kW} / \mathrm{m}^{3}$ respectively) and vacuum freeze-dried mushroom slices. Mean values and standard deviation. Equal letters in the same raw indicate homogeneous groups obtained from LSD intervals $(p<0.05)$. 


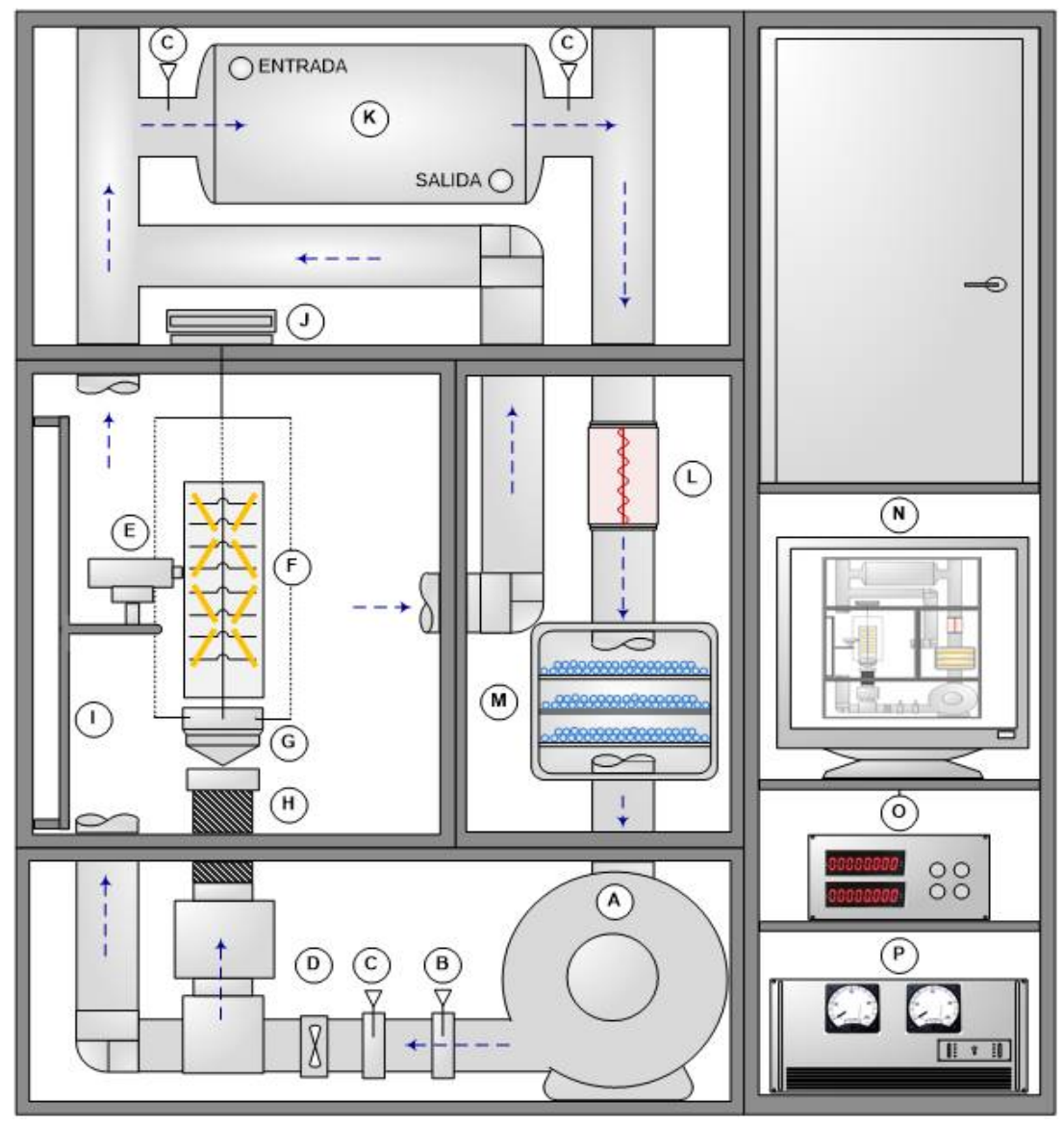

581 Figure 1. Ultrasonically assisted atmospheric freeze drier. A. Fan; B.

582 Temperature sensor, Pt-100; C. Temperature and relative humidity sensor; D.

583 Anemometer; E. Ultrasonic transducer; F. Vibrating drying chamber; G. Sample 584 holder; H. Retreating pipe; I. Vertical displacement mechanism; J. Weighting 585 module; K. Heat exchanger; L. Electric resistance; M. Desiccant material trays; 586 N. Computer, O. Amplifier; P. Resonance dynamic control. 


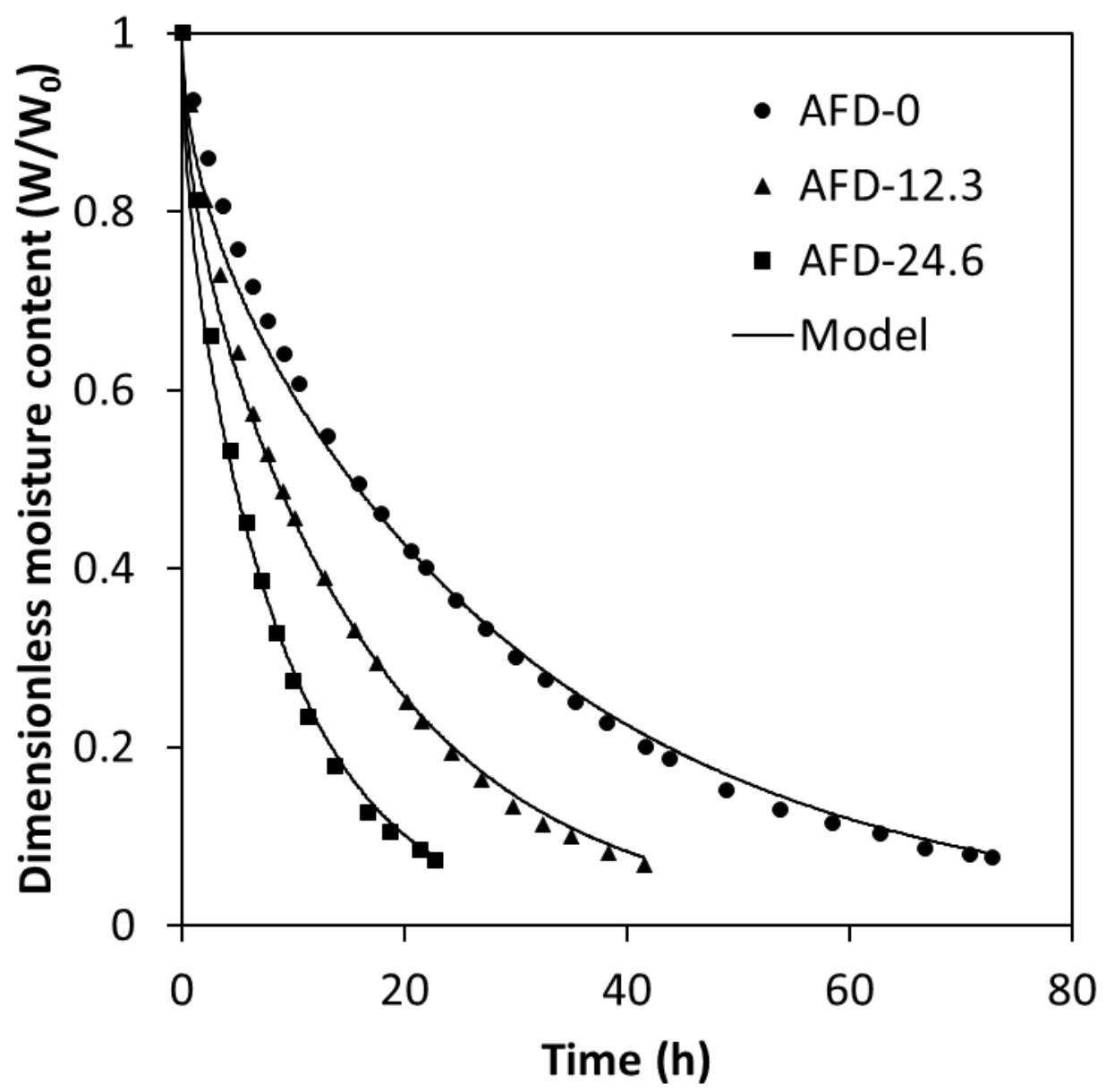

592

593 Figure 2. Experimental and model calculated drying kinetics $\left(-10^{\circ} \mathrm{C}\right.$ and $\left.2 \mathrm{~m} / \mathrm{s}\right)$ of mushroom slices, atmospheric freeze-dried without (AFD-0) and with ultrasound application $(21.9 \mathrm{kHz})$ at different power levels (AFD-12.3 and AFD-24.6 at 12.3 and $24.6 \mathrm{~kW} / \mathrm{m}^{3}$ respectively).

597

598

599

600 


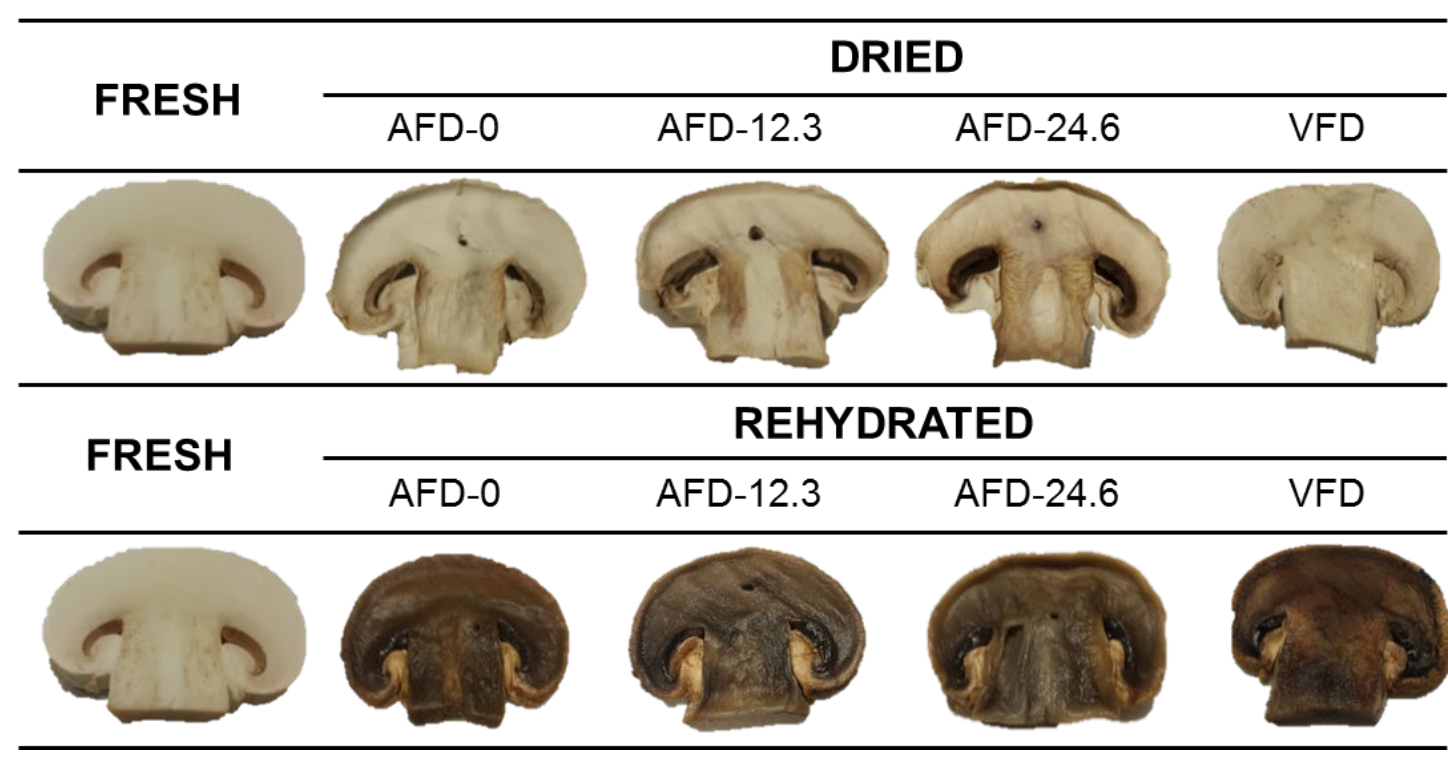

602

Figure 3. Fresh mushroom slices, dried by atmospheric freeze-drying without (AFD-0) and with ultrasound application, at 12.3 (AFD-12.3) and $24.6 \mathrm{~kW} / \mathrm{m}^{3}$ 605 (AFD-24.6), and dried by vacuum freeze-drying (VDF).

606

607

608

609

610

611 


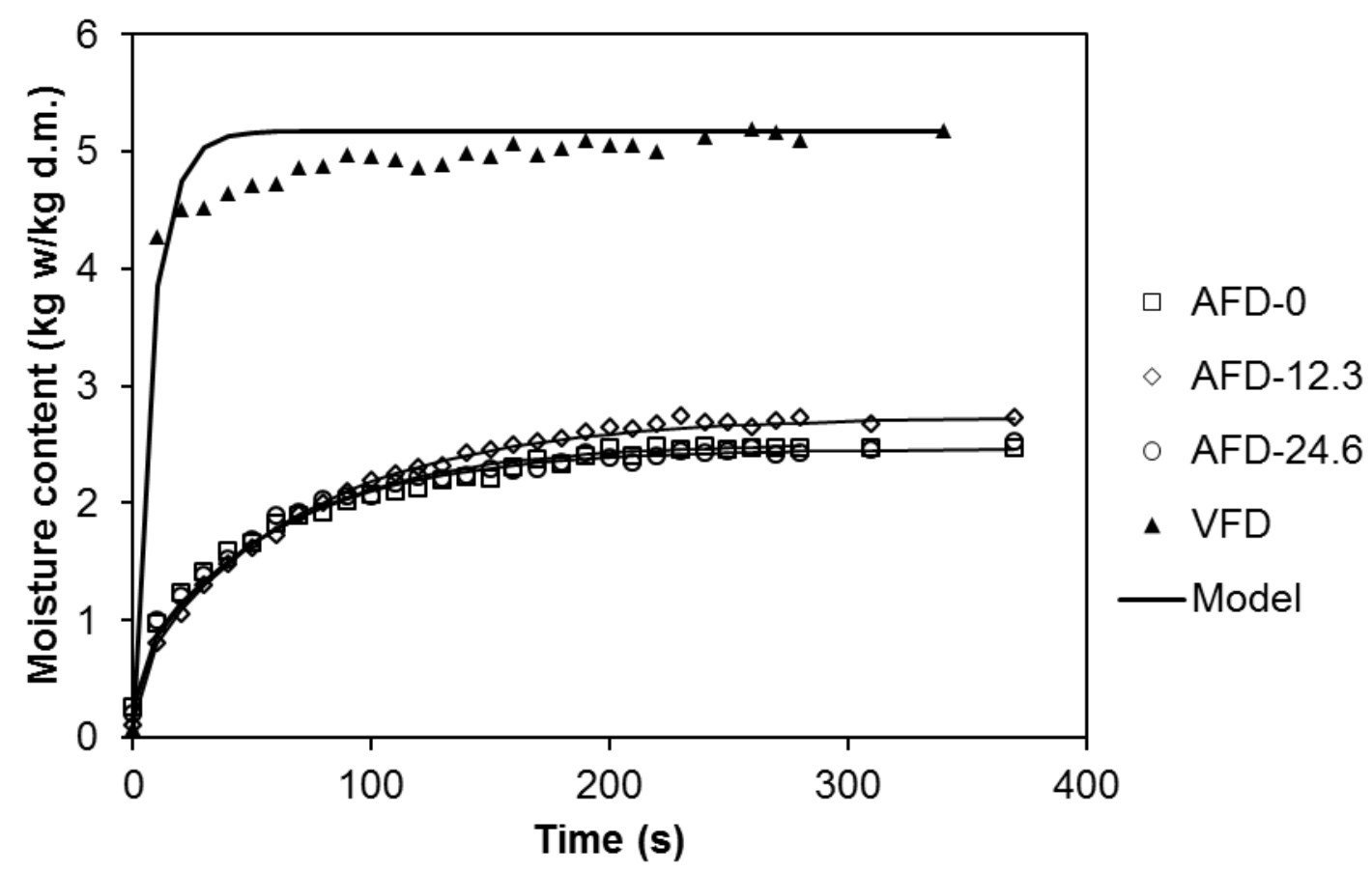

613

614 Figure 4. Experimental and model calculated rehydration kinetics of mushroom slices dried by atmospheric freeze-drying without (AFD-0) and with ultrasound application (AFD-12.3 and AFD-24.6; 12.3 and $24.6 \mathrm{~kW} / \mathrm{m}^{3}$ respectively)) and by

617 vacuum freeze drying (VFD).

618

619

620

621

622

623

624

625

626

627

628

629

630 


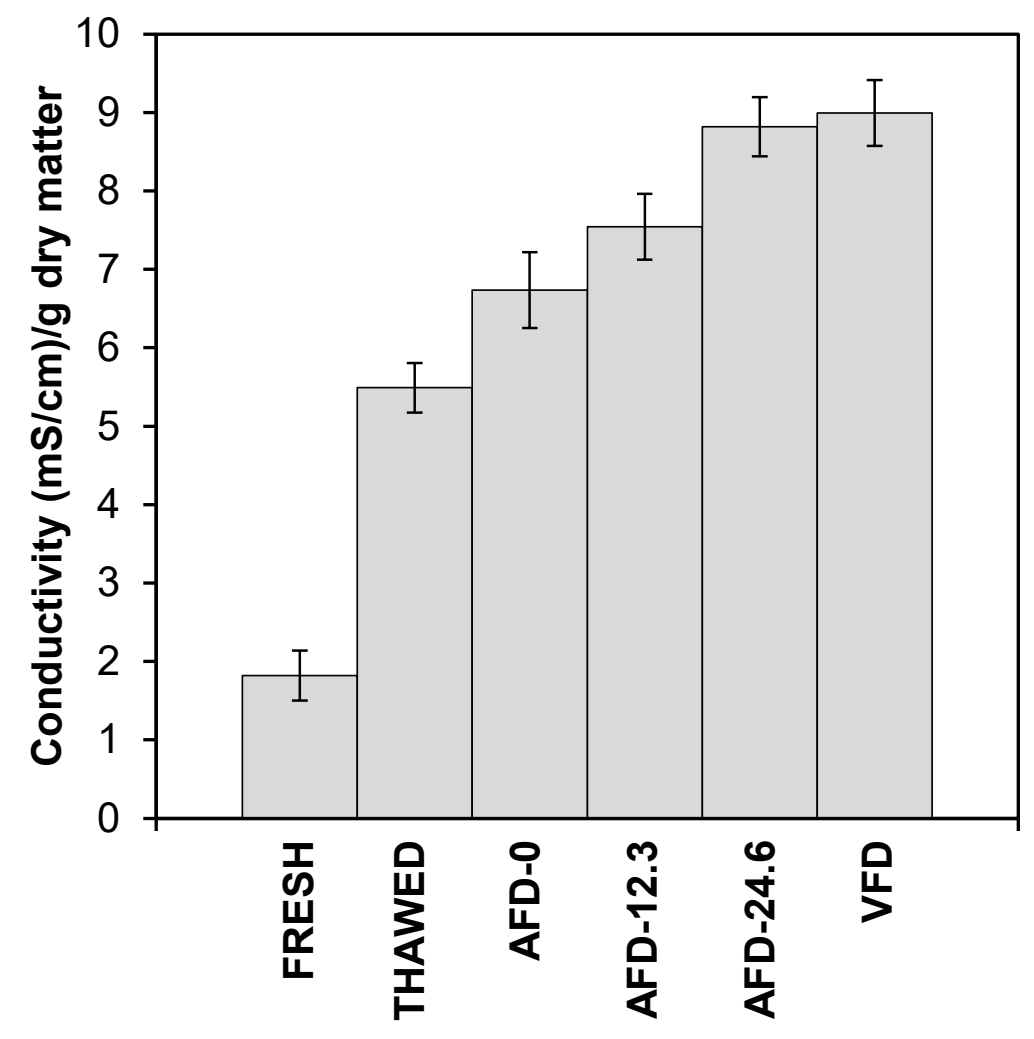

632

633 Figure 5. Influence of the treatment on the conductivity of a solution in contact 634 with samples for $24 \mathrm{~h}$ as a measurement of cell damage. Average values and 635 LSD intervals for fresh, thawed, atmospheric freeze-dried without (AFD-0) and 636 with (AFD-12.3 and AFD-24.6) ultrasound application and vacuum freeze-dried 637 638 mushroom slices (VFD). 
655

656

657

658

659

660

661

662

663

Table 1. CIELAB space color parameters $L^{*}, a^{*}$ and $b^{*}$ of the fresh $(\mathrm{F})$, atmospheric freeze-dried without (AFD-0) and with (AFD-12.3 and AFD-24.6) ultrasound application (12.3 and $24.6 \mathrm{~kW} / \mathrm{m}^{3}$ respectively) and vacuum freezedried mushroom slices (VFD). Total color difference $\left(\Delta E^{\star}\right)$ from fresh values, browning index $(\mathrm{BI})$ and Chroma $\left(C^{*}\right)$. Mean values and standard deviation. Equal letters in the same row indicate homogeneous groups obtained from LSD intervals $(p<0.05)$.

\begin{tabular}{lccccc} 
& FRESH & AFD-0 & AFD-12.3 & AFD-24.6 & VFD \\
\hline $\boldsymbol{L}^{*}$ & $82 \pm 2 \mathrm{a}$ & $72 \pm 4 \mathrm{~b}$ & $57 \pm 2 \mathrm{c}$ & $61 \pm 1 \mathrm{c}$ & $71 \pm 4 \mathrm{~b}$ \\
$\mathbf{a}^{*}$ & $-0.3 \pm 1 \mathrm{a}$ & $0.05 \pm 1 \mathrm{a}$ & $4.1 \pm 0.9 \mathrm{~b}$ & $4 \pm 3 \mathrm{~b}$ & $2.1 \pm 0.5 \mathrm{a}, \mathrm{b}$ \\
$\boldsymbol{b}^{*}$ & $11.2 \pm 0.7 \mathrm{a}$ & $16 \pm 6 \mathrm{~b}$ & $16 \pm 2 \mathrm{~b}$ & $16 \pm 3 \mathrm{~b}$ & $17 \pm 1 \mathrm{a}, \mathrm{b}$ \\
$\boldsymbol{\Delta} \boldsymbol{E}^{*}$ & - & $15 \pm 4 \mathrm{a}$ & $24 \pm 4 \mathrm{~b}$ & $24.3 \pm 0.8 \mathrm{~b}$ & $8 \pm 3 \mathrm{a}$ \\
$\mathbf{B}$ & $15 \pm 4 \mathrm{a}$ & $21 \pm 8 \mathrm{a}, \mathrm{b}$ & $37 \pm 7 \mathrm{c}$ & $34 \pm 8 \mathrm{c}$ & $29 \pm 4 \mathrm{~b}, \mathrm{c}$ \\
$\boldsymbol{C}^{*}$ & $12 \pm 1 \mathrm{a}$ & $14 \pm 4 \mathrm{a}, \mathrm{b}$ & $16 \pm 2 \mathrm{~b}$ & $16 \pm 3 \mathrm{~b}$ & $17 \pm 1 \mathrm{~b}$ \\
\hline
\end{tabular}

Table 2. Textural parameters of fresh samples (FRESH), rehydrated after atmospheric freeze-drying without (AFD-0) and with (AFD-12.3 and AFD-24.6) ultrasound application (12.3 and $24.6 \mathrm{~kW} / \mathrm{m} 3$ respectively) and by vacuum freeze-drying (VFD). Mean values and standard deviation. Equal letters in the same column indicate homogeneous groups obtained from LSD intervals $(p<0.05)$.

\begin{tabular}{lcccc}
\cline { 2 - 5 } & Hardness (N) & Cohesiveness & Elasticity & Chewiness (N) \\
\hline FRESH & $242 \pm 27 \mathrm{a}$ & $0,66 \pm 0,03 \mathrm{a}$ & $0,79 \pm 0,06 \mathrm{a}$ & $131 \pm 2 \mathrm{a}_{\mathrm{a}}$ \\
AFD-0 & $12 \pm 9 \mathrm{~b}$ & $0,64 \pm 0,03 \mathrm{a}$ & $0,86 \pm 0,06 \mathrm{a}$ & $6 \pm 4 \mathrm{~b}$ \\
AFD-12.3 & $13 \pm 5 \mathrm{~b}$ & $0,65 \pm 0,02 \mathrm{a}$ & $0,88 \pm 0,02 \mathrm{~b}$ & $7 \pm 3 \mathrm{~b}$ \\
AFD-24.6 & $5 \pm 3 \mathrm{c}$ & $0,72 \pm 0,05 \mathrm{~b}$ & $0,95 \pm 0,03_{\mathrm{c}}$ & $3 \pm 2 \mathrm{c}$ \\
VFD & $25 \pm 8 \mathrm{~d}$ & $0,59 \pm 0,03 \mathrm{c}$ & $0,70 \pm 0,06 \mathrm{~d}$ & $10 \pm 3 \mathrm{~d}$ \\
\hline
\end{tabular}

Table 3. Rehydration time $(t)$, final moisture content achieved $\left(x_{w f}\right)$ and rehydration identified effective diffusivity $\left(D_{e r}\right)$ of atmospheric freeze-dried without (AFD-0) and with (AFD-12.3 and AFD-24.6) ultrasound application (12.3 and 24.6 $\mathrm{kW} / \mathrm{m}^{3}$ respectively) and vacuum freeze-dried mushroom slices. Mean values and standard deviation. Equal letters in the same row indicate homogeneous groups obtained from LSD intervals $(p<0.05)$.

\begin{tabular}{rcccc}
\cline { 2 - 5 } & AFD-0 & AFD-12.3 & AFD-24.6 & VFD \\
\hline $\boldsymbol{t}(\mathbf{s})$ & $67 \pm 6 \mathrm{a}$ & $132 \pm 31 \mathrm{~b}$ & $183 \pm 31 \mathrm{c}$ & $10 \pm 1 \mathrm{~d}$ \\
$\boldsymbol{X}_{\boldsymbol{w f}}(\mathbf{k g}$ water/kg d.m.) & $6 \pm 1 \mathrm{a}$ & $6.6 \pm 0.4 \mathrm{a}$ & $5.7 \pm 0.2 \mathrm{a}$ & $8 \pm 2 \mathrm{~b}$ \\
$\boldsymbol{D}_{\text {er }}\left(\mathbf{1 0 ^ { - 8 }} \mathbf{~ m}^{\mathbf{2}} / \mathbf{s}\right)$ & $7 \pm 1 \mathrm{a}$ & $5.0 \pm 0.8 \mathrm{a}$ & $6.3 \pm 0.6 \mathrm{a}$ & $32 \pm 9_{\mathrm{b}}$ \\
\hline
\end{tabular}

